\title{
Speech Diagnostics of the Holistic Essence of Personality
}

\section{Речевая диагностика целостной сущности личности}

\author{
Natalia Fomina \\ Dr. in Psychology, \\ Professor \\ Ryazan State University \\ named after S.A. Yesenin, \\ Department of Personality \\ Psychology, Special Psychology \\ and Corrective Pedagogy \\ 46, Svoboda Str., Ryazan, \\ Russia, 390000
}

Наталья Фомина

доктор психологических наук, профессор

\section{E-mail: pslfom@mail.ru \\ orcid.org/0000-0002-5387-7733}

\author{
ФГБОУ ВО «Рязанский \\ государственный университет \\ имени С.А. Есенина», \\ кафедра психологии личности, \\ специиальной психологии и \\ коррекиионной педагогики \\ ул. Свободы, 46, г. Рязань, \\ Россия, 390000
}

Original manuscript received April 21, 2018

Revised manuscript accepted October 19, 2018

\section{ABSTRACT}

The article is devoted to the current interdisciplinary problem of determining the characteristics of a language personality (the term of Yu.N. Karaulov) according to various parameters of her speech, which is located at the junction of psycholinguistics and psychology.

The proposed N.A. Fomina and the scientific concept developed by her together with the pupils for a comprehensive study of personality manifestations in speech activity, which presupposes a systemic consideration of personality traits and a multilevel, multicomponent analysis of the text as a product of individual speech activity. This approach allows you to disclose speech activity in basic features, relationships and relationships, as well as 
provide a more complete and in-depth description of the individuality of the subject of this activity.

The article briefly presents the author's method of polycomponent analysis of the text-statement, giving the opportunity to consider not only its own linguistic (language, speech, meaningful and semantic) characteristics, but also the reflection in it of psychological (motivational, cognitive, dynamic, emotional, regulatory) properties of authors of statements.

Integral variables are named - activity, focus and self-regulation, penetrating all the structural components of the personality and revealing its integral essence through the basic properties.

The possibilities of speech diagnostics of the holistic essence of the personality, which is reflected in its initiative, sociability, and perseverance, characterizing the activity, direction, and regulation of this activity are shown.

Some results of an empirical study of the manifestations of the individualtypological features of these personality traits in her speech are described. Parameters by which it is possible to identify representatives of internally subject, internally-ergic, productive and semantic, selective and aergic types of organization of initiative, sociability, and perseverance, differing from each other primarily by the ratio of different motives and needs, by means of selfregulation and external dynamic manifestations are indicated.

Key words: language personality, speech activity, the integral essence of personality, activity, orientation, self-regulation, language, speech, meaningful characteristics of texts, motivational-targeted, cognitive, emotional, regulatory, dynamic, effective components of speech actions, individual typological features of initiative, sociability, and perseverance.

\section{Вступление}

Как известно, предметом психолингвистики, по А.А. Леонтьеву, является соотношение личности со структурой и функциями речевой деятельности, с одной стороны, и языком как главной «образующей» образа мира человека, с другой (Леонтьев, 1999). Исходя из этого, одной из основных психолингвистических проблем является проявление личности в речи, т.е. деятельности по использованию языковых средств для обозначения объектов действительности, общения, формулирования и выражения мыслей, желаний, эмоций, чувств, регуляции поведения, общения и пр. При этом в индивидуально-психологическом аспекте рассматривают языковую личность - человека в его способности совершать речевые действия или личность, выраженную в языке и через язык (Караулов, 1987). 
Это отражает принцип единства личности и деятельности, который продуктивно разрабатывается в отечественной психологии. Поскольку деятельность есть «момент жизни» и «продукт» личности, любое внешнее действие опосредствуется процессами, протекающими внутри субъекта, а внутренний процесс так или иначе проявляется вовне (Анциферова, 1969), психология через анализ деятельности раскрывает психологический склад личности, ее внутренний, духовный мир и его влияние на эффективность и качество деятельности (Ломов, 1984).

Речевая деятельность, как и всякая другая, также определяется единством двух сторон: внешней, исполнительной, и внутренней, осуществляющей ее организацию, планирование, программирование и т.д. Внутренняя сторона обусловливается сложным единством и взаимодействием функционирования потребностей, мотивов, эмоций, чувств, восприятия, мышления, внимания, памяти, опережающего отражения, свойств темперамента, характера, саморегуляциии т.п., которые выступают в качестве общефункциональных психологических механизмов этой деятельности (Зимняя, 1989) и обеспечивают ее динамику, точность, правильность, связность, последовательность, выразительность, убедительность и успешность. Предметное содержание речевой деятельности составляют ее предмет, т.е. мысль как форма отражения отношений предметов и явлений реальной действительности, в которой реализуется потребность деятельности; определенные средства, т.е. язык как социальную знаковую систему, и способ формирования и формулирования мысли как субъективной формы отражения отношений предметов и явлений объективной действительности посредством языка в процессе речевой деятельности, т.е. речь; продуктом которой являются говорение, письмо в экспрессивной речи, слушание и чтение в речи импрессивной (Зимняя, 1985). Из этого следует, что речь представляет собой единство социального и неповторимо-индивидуального.

Н.А. Фоминой (Мирошкиной) (1992, 2002-2018) предложена и совместно с учениками активно развивается научная концепция целостного анализа проявлений свойств личности в тексте как продукте речевой деятельности, предполагающая системное рассмотрение личностных свойств и многоуровневый, поликомпонентный анализ текста (Мирошкина, 1992; 
Фомина, 2002, 2014). Данная концепция позволяет осуществлять многомерно-функциональный анализ речи, раскрыть речевую деятельность в основных чертах, связях и отношениях, а также дать более полную и глубокую характеристику индивидуальности субъекта этой деятельности.

При этом текст или высказывание рассматривается в широком смысле слова «как определенная совокупная информация, закодированная по системе данного языка» (Клычникова, 1983: 107), «объединенная определенным коммуникативным намерением и воплощающая в себе коммуникативно-познавательную активность индивидов» (Дридзе, 1976: 24). Он воплощает в себе все психологическое содержание речевой деятельности, все условия ее протекания, а также особенности самого субъекта говорения (Зимняя, 1985), т.е. представляет собой объективизацию предмета говорения (мысли), средств (языка) и способа (речи) формирования и формулирования мысли, а также индивидуальных свойств говорящего.

При рассмотрении речевой деятельности мы опираемся на теоретическое положение о поликомпонентной, многомернофункциональной организации действий как единиц конкретных актов поведения и деятельности человека, которые можно рассматривать в качестве единиц анализа индивидуальных проявлений его личности. Действия представляют собой системные, многопризнаковые (поликомпонентные) образования, включающие в себя функциональное единство мотивационных, эмоциональных, когнитивных, операциональных, регуляторных и результативных характеристик, составляющих его внутреннюю природу и общепсихологическую структуру (Крупнов, 1990). Каждый единичный акт деятельности начинается мотивом (мотивационный аспект), который определяет направление деятельности, ее динамику и характер (Зимняя, 1985) и организует всю систему психических процессов и состояний, формирующихся и развертывающихся в ходе деятельности (Ломов, 1984), завершается результатом, достижением намеченной вначале цели, хотя и не всегда внешне выраженным (результативно-продуктивный аспект), в середине же лежит динамическая система конкретных действий и операций, направленных на это достижение (Леонтьев, 1969) (операциональный аспект или механизм деятельности). Действие 
направлено на познание или преобразование окружающей действительности, включая себя и себе подобных (когнитивный или информационно-познавательный компонент), сопровождается эмоциональными переживаниями (эмоциональный аспект) и эмоционально-волевой регуляцией (регуляторно-волевой аспект). Функциональные взаимоотношения вышеназванных компонентов осуществляют непосредственную регуляцию деятельности (и действий) и обусловливают оптимальное приспособление человека к конкретным условиям деятельности в соответствии с теми или иными наличными и потенциальными возможностями индивида (Крупнов, 1990; Крупнов \& Новикова, 2014; Фомина, 2014). Исходя из этого, мы исследуем не только собственно языковые и речевые характеристики речи, но и мотивационный, эмоциональный, когнитивный, регуляторно-волевой, динамический и результативный компоненты речевых действий языковой личности.

Кроме того, мы рассматриваем проявления в речевой деятельности не отдельных характеристик личности, а прежде всего тех ее базовых свойств, которые отражают ее целостную сущность. С точки зрения системного подхода к изучению личности, который предполагает «рассмотрение психического в том множестве внешних и внутренних отношений, в которых оно существует как целостная система» (Ломов, 1984: 88), и с позиций «интегральных переменных личности и индивидуальности», теоретической основой которого является концепция «наиболее общих оснований индивидуальности человека» (Небылицын, 1976), наиболее полно выражают целостную сущность личности ее активность, направленность и саморегуляция. Активность обусловливает внутреннюю потребность индивида к эффективному освоению внешней действительности, к самовыражению относительно внешнего мира, которая может реализоваться в умственном, двигательном (в том числе речедвигательном) или социальном (общение) планах, обеспечивая непрерывное взаимодействие субъекта с миром (Небылицын, 1976: 251). Направление, качество и уровень реализации этой активности определяются «содержательными» особенностями личности, т.е. ее направленностью, представляющей системообразующий компонент структуры и включающей в себя потребности и мотивы, цели, интересы, идеалы, убеждения и мировоззрение, ценностные ориентации и пр. Функции активизации 
и торможения, проявляющиеся в избирательности поведения и принятии решений, осуществляются благодаря сознательной волевой регуляичи активности, которая проявляется в самоконтроле состояний и свойств человека, его характеристик как субъекта деятельности, общения или самосознания, с помощью воли, волевых свойств (Крупнов \& Новикова, 2014: 9-30). Активность, направленность и саморегуляция охватывают все подструктуры личности и проявляются в каждой из них на нейрофизиологическом, психодинамическом, когнитивном, коммуникативно-речевом и характерологическом уровнях своими специфическими характеристиками и признаками.

К сожалению, в большинстве лингвистических исследований, посвященных анализу речи, основное внимание уделяется ее языковым и речевым характеристикам, к которым прежде всего относятся объем словаря, точный подбор слов, правильность грамматического оформления, соблюдение орфоэпических, акцентологических, стилистических, орфографических и пунктуационных норм, связность и целостность текстов, последовательность изложения мыслей и т.д. С психолингвистической точки зрения чаще всего исследуется процесс онтогенеза речевой деятельности (Седов, 2008; Werker, 2018) или когнитивная, смысловая составляющая языкового сознания человека, отраженная в тех или иных концептах или понятиях (Бондарь \& ГордиєнкоМитрофанова, 2017; Бубнова \& Казаченко, 2017; Бутакова, 2018; Сигал, 2018; Gabriel, Gaudrain, Lebrun-Guilland, Sheppard et al., 2012). Лишь немногие изучают репрезентацию в отдельных характеристиках текста как продукта речевой деятельности половых, возрастных, национальных, социальных особенностей субъекта, его эмоциональной, мотивационной, интеллектуальной сфер или частных психологических особенностей человека: замкнутости, озабоченности, осмотрительности, принципиальности, властности, агрессивности или доброжелательности, экстраверсии или интроверсии, экстернальности либо интернальности и др. А отражению в речевых действиях индивидуально-психологических особенностей субъектов речевой деятельности, раскрывающих их как конкретную индивидуальность ихарактеризующих целостную сущность их языковой личности, уделяют недостаточно внимания. 
В то время как необходим комплексный подход к анализу личности как единого лингво-психологического объекта изучения.

Нами ставятся и решаются задачи по исследованию репрезентации базовых свойств целостной языковой личности в лингвистических (языковых, речевых, содержательно-смысловых) характеристиках текстов-высказываний и в психологических (мотивационном, эмоциональном, регуляторно-волевом, когнитивном, динамическом, результативном) компонентах речевых действий.

\section{Методы и методики исследования}

Для получения текста как продукта индивидуальной речевой деятельности респондентам предлагается дать полное и целостное описание какой-либо значимой для них ситуации, которое во многом определяется их индивидуальным жизненным опытом, индивидуальной базой знаний (информационным тезаурусом), а также индивидуальными психологическими особенностями.

С помощью методики (схемы) целостного, поликомпонентного анализа текста как продукта речевой деятельности (Фомина (Мирошкина), 1992, 2002) анализируются лингвистические характеристики высказываний и общепсихологические особенности речевых действий языковой личности.

Лингвистическийанализ текста как продукта индивидуальной речевой деятельности предполагает выявление характеристик средств формирования и формулирования мысли, т.е. языка. В качестве языковых характеристик речевого сообщения (текста) могут выступать объем словаря, вариативность и неповторяемость слов в сообщении или «насыщенность» текста, а также правильность оформления мысли. Речевой уровень анализируется по цельности (смысловому единству) текста, условием которого является связность слов в простом предложении, частей сложного предложения и межфразовые связи текста в целом, а также комплексированности (усложненности) текстов, которая проявляется в дополнительных смысловых связях и однородности членов, во второстепенной предикации, выражаемой обособленными оборотами, в структуре придаточных предложений и т.П. и может рассматриваться как результат более сложной смысловой обработки отражаемых в сознании говорящего связей и отношений предметов и явлений отражаемой действительности. Смысловое содержание текста 
рассматривается с точки зрения отражения различных сторон заданной ситуации (ее денотатной схемы) и выделения различных смысловых связей или категорий смысловой информации (места, времени, действия, причины, условий, признака, состояния и т.д.).

В психологическом плане прежде всего рассматривается мотивационный уровень речевых действий, который может быть представлен характеристиками субъективно-личностного отношения говорящего к предмету высказывания и коммуникативной ориентированности говорящего(по параметрам побудительности и обращенности), субъективации или объективации действий в ситуации, т.е. выбора себя или другого в качестве действующего лица; мотивационно-смысловой направленности стремлений, целей и задач, свидетельствующих о социоцентрической направленности действий на удовлетворение интересов и желаний других либо эгоцентрическом замыкании на своих личных потребностях и мотивах. Вслед за мотивационным компонентом деятельности выделяется эмоциональный компонент, т.к. на всех уровнях порождения речи в той или иной степени отражаются эмоции человека, которые изменяют процесс реализации высказывания во временном плане, отбор языковых средств и способы выражения мысли, модальность высказывания и пр. Эмоциональные характеристики языковой личности проявляются при продуцировании речевого высказывания (текста) в эмоциональной насыщенности текста, эмоциональной окрашенности, модальности субъективно-личных переживаний, а также в смысловых категориях оценочности и размерности, отраженных в высказывании. Регуляторно-волевые характеристики действий анализируются по наличию или отсутствию волевых усилий в действиях, строгой логической последовательности или хаотичности осуществления действий (и переходов от одних этапов к другим), экстернальности, отражающей ориентацию субъекта на внешнюю детерминацию (контроль) событий, или интернальности - т.е. ориентации на зависимость происходящего от собственного поведения, а кроме того, по самоконтролю речевой деятельности, выражающемуся в усилениях, уточнениях или подтверждениях мыслей. К операционально-динамическим характеристикам действий относятся разнообразие, оригинальность или стереотипность приемов и способов ролевых действий в ситуации. Продуктивно-результативный компонент речевых 
действий определяется успешностью их выполнения, о которой свидетельствуют богатство, точность, правильность, связность, последовательность, выразительность речи. Когнитивный компонент характеризуется общей направленностью высказывания на осмысление, анализ ситуации или на ее простое описание. Такой поликомпонентный подход решает задачу комплексного анализа свойств языковой личности: с одной стороны, ее коммуникативнодеятельностных, лингвистических характеристик, с другой характеристик индивидуально-типических, психологических (Фомина (Мирошкина), 1992, 2002, 2014, 2016).

\section{Результаты эмпирического исследования}

В рамках данной концепции под руководством Н.А. Фоминой проведены исследования репрезентации в речи общительности, инициативности, любознательности, отражающих активность личности (Фомина, 2002; Агапова, 2010; Чивилева, 2005); ее направленности, проявляющейся в ценностных ориентациях (Фомина \& Рогожкина, 2013), особенностях образа мира (Гришенина, 2009), своеобразии интеллекта (Елгина, 2006); ответственности, настойчивости и других характеристик эмоционально-волевой саморегуляции (Мирошкина, 1992; Беспалова, 2008; Фомина \& Леева, 2012), а также таких психофизиологических предпосылок формирования личности, как темперамент (Власова, 2007) и соотношение сигнальных систем (Фомина \& Мирчетич, 2014).

В данной статье представлены проявления в речи индивидуально-типологических особенностей общительности, которая является одним из наиболее ярких проявлений направленности и активности в процессе речевой коммуникации; инициативности как основы для психологических проявлений активности личности и настойчивости, которая выполняет функцию регулятора упорной и длительной работы в разных сферах жизни и деятельности.

В исследовании Н.А. Фоминой в зависимости от степени выраженности и соотношений содержательно-смысловых и инструментально-стилевых составляющих вышеназванных свойств определены интернально-субъектный, интернально-эргический, результативно-смысловой, избирательный и аэргический типы их организации, отличающиеся прежде всего соотношением различных 
мотивов и потребностей, способом саморегуляции и внешними динамическими проявлениями (Фомина, 2002).

Эмпирически установлено, что у лиц с интернальносубъектным типом организации общительности и настойчивости тексты отличаются средним объемом, лексической насыщенностью и вариативностью, достаточной грамматической и речевой правильностью и динамичностью повествования. Вместе с тем тексты лиц с данным типом организации общительности характеризуются простотой конструкций, невысокой связностью, последовательностью повествования и соответствием основной теме, а настойчивости и иницииативности - нарушениями логичности и последовательности повествования, а также отступлениями от основной темы. Высказывания лиц с интернально-субъектным типом организации настойчивости, кроме того, максимально усложнены и связны, изобилуют смысловыми категориями пространства и времени, однако содержат минимальное количество причинноследственно-условно-целевых и даже определительных отношений, a в текстах лиц сэтим типоморганизации инициативности, очень небольших по объему, больше, чем в других, служебных и повторяющихся слов, грамматических ошибок и речевых недочетов, наименьшие связность и коэффициент предикативной структурыи очень слаба выраженность всех смысловых категорий. Речевые действия лиц с данным типом организации общзительности, настойчивости и инициативности отличаются явным доминированием эгоцентрической мотивации при минимальной коммуникативной ориентированности текстов, развитой активной регуляцией действий (стремлениями планировать действия, анализировать и оценивать свои поступки, проявлениями силы воли, средствами для уточнения и усиления мыслей). Речевым действиям лиц с данным типом общительности и инищиативности, кроме этого, свойственна очень низкая выраженность эмоционального компонента, общительности - самая низкая осмысленность заданной ситуации, настойчивости - средняя активность и достаточно высокая выразительность за счет общей эмоциональной насыщенности и категорий оценочности; инищиативности пассивность и минимальная описательность.

Тексты лиц с интернально-эргическим типом организации общительности, настойчивости и инициативности имеют 
ярко выраженную эмоциональность, среднюю лексическую насыщенность, вариативность и правильность и нарушения логики повествования. В то же время у лиц с данным типом организации общчттельности средний объем словаря, немало усложняющих элементов, высокая связность текстов; минимальный коэффициент предикативной структуры и выраженность категорий действия, пространства и времени, отступления от основной темы повествования, настойчивости - самый большой объем, отсутствие отступлений от темы, однако минимальная связность, очень много нарушений лексической сочетаемости и последовательности. Тексты лиц с данным типом организации инициитивности характеризуются самым маленьким объемом, почти минимальной лексической вариативностью и насыщенностью, самой низкой грамматической правильностью, самыми простыми и не очень связными синтаксическими конструкциями, слабой выраженностью категорий действия при соответствии основной теме, последовательности и логичности повествования. У лиц с данным типом организации общзительности, настойчивости и инициативности ярко выражен эмоциональный компонент речевых действий; общительности u настойчивости - максимальна активная регуляция. Вместе с этим у представителей интернально-эргическоготипа организации общительности одинаково представлена и социоцентрическая, и эгоцентрическая мотивация, они чаще всех осмысливают ситуацию. Речевые действия лиц с этим типом настойчивости отличаются высокой активностью и максимальной социоцентрической направленностью мотивации, а инищиативности - аэргичностью, самой высокой описательностью и минимальной осмысленностью, выраженностью различных типов мотивации при доминировании эгоцентричности и слабой активной регуляции.

Тексты лиц с результативно-смысловыл типом организации общзительности, настойчивости и иницицативности очень многословны, последовательны; с наибольшим количеством нарушений логики, минимальной выраженностью категорий признака и состояния, а максимальной - категорий действия. Текстам лиц с данным типом организации общзительности $u$ настойчивости свойственны большое количество незначимых слов, средняя усложненность конструкций и соответствие основной теме. Различия заключаются в том, что высказывания лиц с 
результативно-смысловым типом организации общительности изобилуют повторами, отличаются средней грамматической правильностью и наименьшей связностью; настойчивости содержат много грамматических ошибок, больше, чем остальные, ошибок в выборе слов, отличаются средней связностью; инициативности - имеют немного служебных слов и повторов, очень мало грамматических ошибок и речевых недочетов, очень большую связность, максимальную усложненность, однако минимум категорий признака и состояния, много нелогичности и отклонений от описания или осмысления заданной ситуации. Речевые действия лиц с результативно-смысловым типом организации общительности, настойчивости и инициативности объединяет преобладание описательности в когнитивном компоненте. Действия лиц с данным типом общительности и настойчивости характеризуются яркой выраженностью эгоцентрической мотивации и экстернальной регуляции при очень низких показателях усиления и уточнения мыслей, а также невысокой эмоциональностью. Для речевых действий лиц с данным типом организации настойчивости характерна пассивность, инициативности - средняя активность, достаточная эмоциональность, как социоцентрическая, так и эгоцентрическая мотивация при наибольшей выраженности первой, самая высокая коммуникативная ориентированность текстов и хорошо развитая интернальная регуляция.

Высказывания лиц $c$ избирательным типом организации общительности, настойчивости и инициативности очень небольшого объема, достаточно сложные и связные, но со слабой выраженностью категорий действия, отступлениями от основной темы повествования, нелогичностью в построении предложений или в передаче информации. В текстах лиц с данным типом организации общительности и настойчивости низкий коэффициент предикативной структуры, настойчивости и инищиативности самые высокие показатели категорий состояния и признака, достаточно представлены сложные смысловые категории причины, следствия, цели и условия, однако встречается непоследовательность повествования. Вместе с тем тексты лиц с избирательным типом организации общительности выделяются максимальным количеством грамматических ошибок, нарушений в отборе слов и лексической сочетаемости, а также слабой выраженностью 
всех смысловых категорий; настойчивости - в основном состоят из лексически значимых слов (которые чаще, чем в других, повторяются), содержат очень немного грамматических ошибок и случаев неправильного выбора слов при достаточном количестве нарушений лексической сочетаемости; а с избирательным типом иницииативности - мало повторяющихся и служебных слов, среднее количество грамматических и немного речевых ошибок, высокий коэффициент предикативной структуры. Речевые действия лиц с даннылм типом организации общительности, настойчивости u инициативности определяются высокой эмоциональностью и максимальной осмысленностью ситуации. В то же время действиям лиц с данным типом настойчивости и иницичативности более свойственна экстернальная регуляция, а общзительности интернальная; у лиц с избирательным типом организации общзительности и настойчивости преобладает эгоцентрическая мотивация при низкой коммуникативной ориентированности текстов, а инициативности - присутствуют оба типа мотивации действий; речевые действия лиц с этим типом настойчивости характеризуются пассивностью, а инициативности - средней активностью.

В высказываниях лиц с аэргическим типом организации общчительности, настойчивости и иницииативности минимальное количество незначимых слов, очень высокие связность и усложненность, максимальные коэффициент предикативной структуры и выраженность смысловых категорий пространства, времени, причины, следствия, цели и условия. Тексты лиц с данным типом организации общзительности и настойчивости объединяет небольшой объем, стройность и последовательность повествования; общзительности и инициативности - максимальная лексическая вариативность, достаточно грамотное оформление, отсутствие отклонений от темы. Вместе с тем тексты лиц с аэргическим типом общительности отличаются самыми высокими показателями категорий признака и яркой выраженностью категорий состояния; настойчивости - максимальным количеством грамматических ошибок при минимальной представленности категорий признака и состояния; инициативности - немалым количеством алогизмов и максимальным - нарушений последовательности повествования. Речевым действиям лиц с 
аэргическим типом организации общительности и инищиативности свойственны доминирование эгоцентрической направленности при минимальной коммуникативной ориентированности текстов (или ее отсутствии), преобладание осмысленности над описательностью, ярко выраженная активная регуляция. Действиям лиц с данным типом организации настойчивости и инцииативности присуща минимальная эмоциональность, а общительности - самая высокая эмоциональная насыщенность. Речевые действия лиц с этим типом организации настойчивости отличаются некоторой активностью, самой низкой осмысленностью ситуации, полным отсутствием социоцентричности, выраженной эгоистической мотивацией либо отсутствием ярко выраженной мотивации вообще, представленностью и активной, и пассивной регуляции, аинициативности - средней активностью (Фомина, 2002).

\section{Выводы}

Таким образом, представленный в данной статье системный подход к анализу проявлений языковой личности в текстевысказывании демонстрирует широкие возможности оперативной экспресс-диагностики еe устойчивых коммуникативно-речевых и индивидуально-психологических свойств через речь.

\section{Литература}

Агапова, А.Ю. Особенности общительности менеджеров и педагогов и их проявления в речи : автореф. дисс. ... канд. психол. наук. Москва, 2010.

Анциферова, Л.И. Принцип связи психики и деятельности и методология психологии. Методологические и теоретические проблемы психологии. Москва : Наука, 1969. С. 61.

Беспалова, Т.М. Ответственность старшеклассников и курсантов военного вуза и её проявления в речевой деятельности : автореф. дисс. ... канд. психол. наук. Москва, 2008. 25 с.

Бондарь, Ю., Гордиенко-Митрофанова, И. Влияние пола на вербальное поведение респондентов поздней зрелости при исследовании стимула «игривость». Psycholinguistics. Психолингвистика. Психолінгвістика. 2017. Вып. 21(1). C. $65-85$.

Бубнова И., Казаченко, О. Динамика смыслового содержания значения слова «свобода». Psycholinguistics. Психолингвистика. Психолінгвістика. 2018. Вып. 23(2). C. 11-14. https://doi.org/10.5281/zenodo.1199099

Бутакова, Л. Старость как концептуальный феномен: региональные и возрастные аспекты ассоциативной семантики. Psycholinguistics. Психолингвистика. Психолінгвістика. 2018. Вып. 23(2). С. 25-39. https://doi.org/10.5281/ zenodo. 1205003 
Власова, Л.А. Темперамент и его проявления в лингвистических и психологических характеристиках речи : автореф. дисс. ... канд. психол. наук. Москва, 2007. 26 с.

Гришенина, Ю.А. Национальные особенности образа мира и их проявления в речевой деятельности российских, индийских и африканских студентов : автореф. дисс. ... канд. психол. наук. Москва, 2009. 24 с.

Дридзе, Т.М. Текст как иерархия коммуникативных программ. Смысловое восприятие речевого сообщения. Москва : Наука, 1976. С. 24.

Елгина, С.В. Проявления интеллектуальных особенностей личности в речевой деятельности : автореф. дисс. ... канд. психол. наук. Москва, 2006. 24 с.

Зимняя, И.А. Психологические аспекты обучения говорению на иностранном языке. Москва : Просвещение, 1985.

Зимняя, И.А. Психология обучения неродному языку. Москва : Русский язык, 1989.

Караулов, Ю.Н. Русский язык и языковая личность. Москва : Наука, 1987. 263 с.

Клычникова, 3.И. Психологические особенности обучения чтению на иностранном языке. Москва : Просвещение, 1983.

Крупнов А.И., Новикова И.А. История и концептуальные основы системнофункционального подхода к исследованию свойств личности. Системные исследования свойств личности: к 30-летию научной школь А.И. Крупнова в РУДН : [коллективная монография] / Научные редакторы А.И. Крупнов, С.И. Кудинов, Н.А. Новикова. Москва : РУДН, 2014. С. 9-30.

Крупнов, А.И. Психологическая структура действий человека. Москва : Изд-во УДН, 1990. 56 с.

Леонтьев, А.А. Психолингвистические единицы и порождение речевого высказывания. Москва : Наука, 1969.

Ломов, Б.Ф. Методологические и теоретические проблемы психологии. Москва : Наука, 1984.

Мирошкина, Н.А. Типы саморегуляции и индивидуальные различия в речевой деятельности студентов : автореф. дисс. ... канд. психол. наук. Москва, 1992. $22 \mathrm{c}$.

Небылицын, В.Д. Психофизиологические исследования индивидуальных различий. Москва : Наука, 1976.

Седов, К.Ф. Онтопсихолингвистика: становление коммуникативной компетенции человека. Москва : Лабиринт, 2008. 320 с.

Сигал, К. Семантическая доминанта противительного союза «зато» в зеркале конструктивного эксперимента. Psycholinguistics. Психолингвистика. Психолінгвістика. 2018. Вып. 23(2). С. 214-222. https://doi.org/10.5281/ zenodo. 1199226

Фомина, Н.А. Индивидуально-типические особенности свойств личности и их проявления в речи : автореф. дисс. ... докт. психол. наук. Москва, 2002. 54 с.

Фомина, Н.А. Проявления личности в речи : монография. Рязань : РГУ имени С.А. Есенина, 2016. 141 с.

Фомина, Н.А. Проявления различных свойств языковой личности в речевой деятельности. Системные исследования свойств личности: к 30-летию научной школь А.И. Крупнова в РУДН : [коллективная монография] / Научные редакторы А.И. Крупнов, С.И. Кудинов, Н.А. Новикова. Москва : РУДН, 2014. С. 446-473.

Фомина, Н.А. Свойства личности и особенности речевой деятельности : [монография]. Рязань : «Узорочье», 2002. 362 с. 
Фомина, Н.А., Леева, А.Н. Общительность и выраженность в речи особенностей эмоционально-волевой сферы личности учителей-логопедов. Психолингвистика. 2012. Вып. 10. С. 120-129.

Фомина, Н.А., Мирчетич, М.А. Лингвистические характеристики текстов и психологические особенности речевых действий студентов с доминированием различных сигнальных систем. East European Journal of Psycholinguistics. 2014. Is. 1. P. 8-17.

Фомина, Н.А., Мирчетич, М.А. Психологические характеристики продуктов речевой деятельности студентов с преобладанием различных сигнальных систем. Системные исследования свойств личности: $к$ 30-летию научной школь А.И. Крупнова : [коллективная монография] / Научн. ред. А.И. Крупнов, С.И. Кудинов, И.А. Новикова. Москва : РУдН, 2014. C. 491-496.

Фомина, Н.А., Рогожкина, Т.В. Жизненные смыслы и ценности студентов, «плывущих по течению». Психолого-педагогический поиск. 2013. № 2. C. $162-169$.

Фомина, Н.А., Рогожкина, Т.В. Смысложизненные ориентации и речевая деятельность студентов, нацеленных на будущее. Российский научный журнал. Серия «История. Педагогика. Психология. Философия. Право». 2013. № 2(33). С. 104-111.

Чивилева, И.В. Проявления личностных характеристик активности в речевой деятельности : автореф. дисс. ... канд. психол. наук. Москва, 2005.

Gabriel, D., Gaudrain, E., Lebrun-Guilland, G., Sheppard, F., Tomescu, I., \& Schnider, M. (2012). Do Irrelevant Sounds Impair the Maintenance of All Characteristics of Speech in Memory? Journal of Psycholinguistic Research, 41(6), 475-486. DOI: 10.1007/s10936-012-9204-8

Werker, Janet F. (2018). Perceptual beginnings to language acquisition. Applied Psycholinguistics, 39(4), 703-729. doi:10.1017/s0142716418000152

\section{References}

Agapova, A.Yu. (2010). Osobennosti obshchitelnosti menedzherov i pedagogov i Ih proyavleniya $\mathrm{v}$ rechi [Features of managers and teachers sociability and their manifestations in speech]. Extended abstract of candidate's thesis. Moscow [in Russian].

Anciferova, L.I. (1969). Princip svyazi psihiki i deyatelnosti i metodologiya psihologii [The principle of connection berween the psyche and the activities and methodology of psychology]. Metodologicheskie $i$ teoreticheskie problemy psihologii - Methodological and theoretical problems of psychology (p. 61). Moscow : Nauka [in Russian].

Bespalova, T.M. (2008). Otvetstvennost starsheklassnikov i kursantov voennogo vuza $\mathrm{i}$ eyo proyavleniya $\mathrm{v}$ rechevoj deyatelnosti [Responsibility of higher school students and cadets of a military college and its manifestation in speech activity]. Extended abstract of candidate's thesis. Moscow [in Russian].

Bondar, Y.S., \& Hordiyenko-Mytrofanova, I.V. (2017). Vliyanie pola na verbvlnoe povedenie respondentov pozdnej zrelosti pri issledovanii stimula «igrivost» [The influence of gender on the verbal behavior of old age respondents within the framework of research the stimulus word «playfulness»]. Psiholingvistika Psycholinguistics, 21(1), 65-85 [in Russian]. 
Bubnova, I., \& Kazachenko, O. (2018). Dinamika smyslovogo soderzhaniya znacheniya slova «svoboda» [Dynamics of the Semantic Content of the Word Freedom]. Psiholingvistika - Psycholinguistics, 23(2), 11-14. https://doi. org/10.5281/zenodo.1199099 [in Russian].

Butakova, L. (2018). Starost kak konceptualnyj fenomen: regionalnye i vozrastnye aspekty associativnoj semantiki [Old Age as a Conceptual Phenomenon: Regional and Age Aspects of Associtive Semantics]. Psiholinguistika - Psycholinguistics, 23(2), 25-39. https://doi.org/10.5281/zenodo.1205003 [in Russian].

Vlasova, L.A. (2007). Temperament i ego proyavleniya v lingvisticheskih i psihologicheskih harakteristikah rechi [Temperament and its manifestations in linguistic and psychological characteristics of speech]. Extended abstract of candidate's thesis. Moscow [in Russian].

Grishenina, Yu.A. (2009). Nacionalnye osobennosti obraza mira i ih proyavleniya $\mathrm{v}$ rechevoj deyatelnosti rossijskih, indijskih i afrikanskih studentov [National features of the image of world and their manifestations in the speech activities of Russian, Indian and African students]. Extended abstract of candidate's thesis. Moscow [in Russian].

Dridze, T.M. (1976). Tekst kak ierarhiya kommunikativnyh program [Text as a hierarchy of the communication programs]. Smyslovoe vospriyatie rechevogo soobshcheniya - The semantic perception of speech messages (p. 24). Moscow : Nauka [in Russian].

Elgina, S.V. (2006). Proyavleniya intellektualnyh osobennostej lichnosti v rechevoj deyatelnosti [Manifestations of the intellectual peculiarities of personality in speech activity]. Extended abstract of candidate's thesis. Moscow [in Russian].

Zimnyaya, I.A. (1985). Psihologicheskie aspekty obucheniya govoreniyu na inostrannom yazyke [Psychological aspects of teaching to speak in a foreign language]. Moscow : Prosveshchenie [in Russian].

Zimnyaya, I.A. (1989). Psihologiya obucheniya nerodnomu yazyku [Psychology of teaching non-native language]. Moscow : Russkijyazyk [in Russian].

Karaulov, Yu.N. (1987). Russkij yazyk i yazykovaya lichnost [Russian language and language personality]. Moscow : Nauka [in Russian].

Klychnikova, Z.I. (1983). Psihologicheskie osobennosti obucheniya chteniyu na inostrannom yazyke [Psychological features of teaching reading in a foreign language]. Moscow : Prosveshchenie [in Russian].

Krupnov, A.I., \& Novikova, I.A. (2014). Istoriya i konceptualnye osnovy sistemnofunkcionalnogo podhoda $\mathrm{k}$ issledovaniyu svojstv lichnosti [History and conceptual foundations of the system-functional approach to study of the personality traits]. Sistemnye issledovaniya svojstv lichnosti: $k$ 30-letiyu nauchnoj shkoly A.I. Krupnova $v$ RUDN - Systemic studies of the personality traits: to the $30^{\text {th }}$ anniversary of the scientific school of A.I. Krupnov in Russian University of Peoples' Friendship] (pp. 9-30). In A.I. Krupnov, S.I. Kudinov \& N.A. Novikova (Eds.). Moscow : RUDN [in Russian].

Krupnov, A.I. (1990). Psihologicheskaya struktura dejstvij cheloveka [Psychological structure of human actions]. Moscow : Izd-vo UDN [in Russian].

Leontev, A.A. (1969). Psiholingvisticheskie edinicy $i$ porozhdenie rechevogo vyskazyvaniya [Psycholinguistic Units and Generation of Speech]. Moscow : Nauka [in Russian].

Lomov, B.F. (1984). Metodologicheskie $i$ teoreticheskie problemy psihologii [Methodological and theoretical problems of psychology]. Moscow : Nauka [in Russian]. 
Miroshkina, N.A. (1992). Tipy samoregulyacii i individualnye razlichiya $\mathrm{v}$ rechevoj deyatelnosti studentov [Types of self-regulation and individual differences in speech activity of students]. Extended abstract of candidate's thesis. Moscow [in Russian].

Nebylicyn, V.D. (1976). Psihofiziologicheskie issledovaniya individualnyh razlichij [Psychophysiological studies of individual differences]. Moscow : Nauka [in Russian].

Sedov, K.F. (2008). Ontopsiholingvistika: stanovlenie kommunikativnoj kompetencii cheloveka [Ontopsycholinguistics: the formation of human communicative competence]. Moscow : Labirint [in Russian].

Seagal, K. (2018). Semanticheskaya dominanta protivitelnogo soyuza «zato» V zerkale konstruktivnogo ehksperimenta [The Semantic Dominant of Adversative Conjunction «Zato» ('But') in the Mirror of Constructive Experiment]. Psiholinguistika - Psycholinguistics, 23(2), 214-222. https://doi.org/10.5281/ zenodo.1199226 [in Russian].

Fomina, N.A. (2002). Individualno-tipicheskie osobennosti svojstv lichnosti i ih proyavleniya $\mathrm{v}$ rechi [Individually typical features of personality traits and their manifestations in speech]. Extended abstract of Doctor's thesis. Moscow [in Russian].

Fomina, N.A. (2016). Proyavleniya lichnosti v rechi [Personality manifestations in speech]. Ryazan : RGU imeni S.A. Esenina [in Russian].

Fomina, N.A. (2014). Proyavleniya razlichnyh svojstv yazykovoj lichnosti v rechevoj deyatelnosti [Manifestations of various properties of the linguistic personality in speech activity]. Sistemnye issledovaniya svojstv lichnosti: $k$ 30-letiyu nauchnoj shkoly A.I. Krupnova v RUDN - Systemic studies of the personality traits: to the 30th anniversary of the scientific school of A.I. Krupnov in Russian University of Peoples' Friendship] (pp. 446-473). In A.I. Krupnov, S.I. Kudinov \& N.A. Novikova (Eds.). Moscow : RUDN [in Russian].

Fomina, N.A. (2002). Svojstva lichnosti i osobennosti rechevoj deyatelnosti [Properties of personality and features of speech activity]. Ryazan : «Uzoroche» [in Russian].

Fomina, N.A., \& Leeva, A.N. (2012). Obshchitelnost i vyrazhennost v rechi osobennostej ehmocionalno-volevoj sfery lichnosti uchitelej-logopedov [Sociability and expressiveness in speech of the features of emotional-volitional sphere of the personality of speech therapist teachers]. Psiholingvistika Psycholinguistics, 10, 120-129 [in Russian].

Fomina, N.A., \& Mirchetich, M.A. (2014). Lingvisticheskie harakteristiki tekstov i psihologicheskie osobennosti rechevyh dejstvij studentov $\mathrm{s}$ dominirovaniem razlichnyh signalnyh system [Linguistic characteristics of texts and psychological features of speech actions of students with the dominance of various signal systems]. East European Journal of Psycholinguistics, 1, 8-17 [in Russian].

Fomina, N.A., \& Mirchetich, M.A. (2014). Psihologicheskie harakteristiki produktov rechevoj deyatelnosti studentov $\mathrm{s}$ preobladaniem razlichnyh signalnyh system [Psychological characteristics of the products of students' speech activity with a predominance of various signal systems]. Sistemnye issledovaniya svojstv lichnosti: $k$ 30-letiyu nauchnoj shkoly A.I. Krupnova - Systemic studies of the personality traits: to the 30th anniversary of the scientific school of A.I. Krupnov in Russian University of Peoples' Friendship] (pp. 491-496). In A.I. Krupnov, S.I. Kudinov \& N.A. Novikova (Eds.). Moscow : RUDN [in Russian].

Fomina, N.A., \& Rogozhkina, T.V. (2013). Zhiznennye smysly i cennosti studentov, «plyvushchih po techeniyu» [The life meanings and values of students 'floating 
with the flow']. Psihologo-pedagogicheskij poisk - Psycho-pedagogical search, 2, 162-169 [in Russian].

Fomina, N.A., \& Rogozhkina, T.V. (2013). Smyslozhiznennye orientacii i rechevaya deyatelnost studentov, nacelennyh na budushchee [Life orientation and speech activities of students aimed at the future]. Rossijskij nauchnyj zhurnal. Seriya «Istoriya. Pedagogika. Psihologiya. Filosofiya. Pravo» - Russian scientific journal. Series «History. Pedagogy. Psychology. Philosophy. Right», 2(33), 104 111 [in Russian].

Chivileva, I.V. (2005). Proyavleniya lichnostnyh harakteristik aktivnosti v rechevoj deyatelnosti [Manifestations of the personal characteristics in speech activity]. Extended abstract of candidate's thesis. Moscow [in Russian].

Gabriel, D., Gaudrain, E., Lebrun-Guilland, G., Sheppard, F., Tomescu, I., \& Schnider, M. (2012). Do Irrelevant Sounds Impair the Maintenance of All Characteristics of Speech in Memory? Journal of Psycholinguistic Research, 41(6), 475-486. DOI: 10.1007/s10936-012-9204-8

Werker, Janet F. (2018). Perceptual beginnings to language acquisition. Applied Psycholinguistics, 39(4), 703-729. doi:10.1017/s0142716418000152

\section{АННОТАЦИЯ}

Статья посвящена актуальной междисциплинарной проблеме определения особенностей языковой личности (термин Ю.Н. Караулова) по различным параметрам ее речи, и которая находится на стыке психолингвистики и психологии.

Раскрыта предложенная Н.А. Фоминой и разрабатываемая ею совместно с учениками научная концепция по комплексному исследованию проявлений личности в речевой деятельности, которая предполагает системное рассмотрение личностных свойств и многоуровневый, поликомпонентный анализ текста как продукта индивидуальной речевой деятельности. Данный подход позволяет раскрывать речевую деятельность в основных чертах, связях и отношениях, а также давать более полную и глубокую характеристику индивидуальности субъекта этой деятельности.

В статье кратко представлена авторская методика поликомпонентного анализа текста-высказывания, дающая возможность рассматривать не только его собственно лингвистические (языковые, речевые, содержательно-смысловые) характеристики, но и отражение в нем психологических (мотивационноцелевых, когнитивных, динамических, эмоциональных, регулятивных) свойств авторов высказываний.

Названы интегральные переменные - активность, направленность и саморегуляция, пронизывающие все структурные компоненты личности и раскрывающие ее целостную сущность через базовые свойства. 
Показаны возможности речевой диагностики целостной сущности личности, которая отражается в ее инициативности, общительности и настойчивости, характеризующих активность, направление и регуляцию этой активности.

Описаны некоторые результаты эмпирического исследования проявлений индивидуально-типологических особенностей данных свойств личности в ее речи. Указаны параметры, по которым возможно идентифицировать представителей интернальносубъектного, интернально-эргического, результативно-смыслового, избирательного и аэргического типов организации инициативности, общительности и настойчивости, отличающихся друг от друга прежде всего соотношением различных мотивов и потребностей, способом саморегуляции и внешними динамическими проявлениями.

Ключевые слова: языковая личность, речевая деятельность, целостная сущность личности, активность, направленность, саморегуляция, языковые, речевые, содержательно-смысловые характеристики текстов, мотивационно-целевые, когнитивные, эмоциональные, регулятивные, динамические, результативные компоненты речевых действий, индивидуально-типологические особенности инициативности, общительности и настойчивости.

\section{Фоміна Наталія. Мовленнєва діагностика цілісної сутності особистості}

\section{АНОТАЦІЯ}

Стаття присвячена актуальній міждисциплінарній проблемі визначення особливостей мовної особистості (термін Ю.М. Караулова) за різними параметрами ії мовлення, і яка знаходиться на перетині психолінгвістики і психології.

Розкрито запропоновану Н.О. Фоміною і розроблену нею спільно з учнями наукову концепцію комплексного дослідження проявів особистості в мовленнєвій діяльності. Ця концепція передбачає системний розгляд особистісних властивостей і багаторівневий, полікомпонентний аналіз тексту як продукту індивідуальної мовленнєвої діяльності. Даний підхід дозволяє розкрити мовленнєву діяльність в основних рисах, зв'язках і відношеннях, а також повніше й глибше охарактеризувати індивідуальність суб'єкта чієї діяльності.

у статті в узагальненому вигляді представленао авторську методику полікомпонентного аналізу тексту-висловлювання, яка дає можливість розглядати не тільки його власне лінгвістичні (мовні, мовленнєві, змістовно-смислові) характеристики, а й відображення у 
тексті психологічних (мотиваційно-цільових, когнітивних, динамічних, емоційних, регулятивних) властивостей авторів висловлювань.

Названо інтегральні змінні - активність, спрямованість і саморегуляція, що пронизують всі структурні компоненти особистості й розкривають ї̈ цілісну сутність через базові властивості.

Показані можливості мовленнєвої діагностики цілісної сутності особистості, яка виражається в ії ініціативності, комунікативності й наполегливості, що характеризують активність, спрямування й регуляцію цієї активності. Описані деякі результати емпіричного дослідження проявів індивідуально-типологічних особливостей цих властивостей особистості в їі мовленні. Названі параметри, за якими можливо ідентифікувати представників інтернально-суб'єктного, інтернально-ергічного, результативносмислового, вибірковогойаергічного типів організації ініціативності, комунікативності й наполегливості, що відрізняються один від одного перш за все співвідношенням різних мотивів і потреб, способом саморегуляції й зовнішніми динамічними проявами.

Ключові слова: мовна особистість, мовленнєва діяльність, цілісна сутність особистості, активність, спрямованість, саморегуляція, мовні, мовленнєві, змістовно-смислові характеристики текстів, мотиваційноцільові, когнітивні, емоційні, регулятивні, динамічні, результативні компоненти мовленнєвих дій, індивідуально-типологічні особливості ініціативності, комунікативності й наполегливості. 